\title{
Intervenção no processo ensino-aprendizagem do desenho técnico
}

Intervention in the teaching and learning process of technical drawing.

SANTOS, Luiz R. da S.; Especialista em Docência no Ensino Técnico e Superior; UNITOLEDO,

Araçatuba

luizrobertosantos5@gmail.com

BONI, Claudio R.; Doutorando, FAAC, UNESP - Univ Estadual Paulista, Bauru

claudioboni@hotmail.com

\section{Resumo}

As áreas de formação técnica ou tecnológica têm em sua base curricular o ensino do desenho técnico, que é definido como um conjunto de normas para representação visual de objetos, com o objetivo principal de comunicar dados ou informações. A primeira parte desta pesquisa identificou, através da pesquisa-ação, os problemas de ensino-aprendizagem na matéria de desenho técnico do curso de automação industrial do Instituto Federal de São Paulo (IFSP) de Birigui. Na sequência, a intervenção pedagógica se deu por meio de um plano de ação aplicado em forma de um minicurso através do software tridimensional denominado Autodesk ${ }^{\circledR}$ Inventor ${ }^{\circledR}$. O estudo contribuiu para compreender melhor as dificuldades que os alunos encontram para aprenderem o desenho técnico e como intervir para reforçar os conceitos básicos, visando à formação profissional do estudante.

Palavras Chave: Desenho técnico; Intervenção; Pesquisa-ação.

\begin{abstract}
The curriculum of technical and technological areas has the technical drawing teaching as part of its base because these rules are used to make a visual communication of elements of the project and to supply data and information. The first part of this research shows the main problems in the teaching and learning of the technical drawing in the industrial automation course at Instituto Federal de São Paulo based in Birigui. The method used was the Research Action Participant. In the second part, it was made an action plan to create a pedagogical intervention using Autodesk ${ }^{\circledR}$ Inventor ${ }^{\circledR}$ workshops as the approach. The study contributed to increasing the comprehension of students difficulties in terms of technical drawing learning and to create a strategy to improve the basic knowledge aiming the student professional formation.
\end{abstract}

Keywords: technical drawing; intervention; action-research. 


\section{Introdução}

O desenho técnico é definido como um conjunto de normas para representação visual de objetos, com o propósito de prover informações essenciais para analisar, desenvolver e facilitar a concepção ou manutenção e, por consequência, identificar as dificuldades do processo de ensinoaprendizagem, tornando-o contextualizado e próximo da realidade dos alunos.

Esta abordagem também buscou otimizar a utilização dos recursos tridimensionais gráficos ou físicos para exemplificar conceitos do desenho técnico, destacando as seguintes temáticas: a importância do desenho técnico para o profissional da automação industrial, compreender as linguagens técnicas do desenho, os conceitos básicos das vistas ortogonais e os benefícios das anotações, mesmo que dentro de um curso de desenho.

A pesquisa-ação foi utilizada como metodologia, uma vez que possui fundamentos a viabilizar a mediação entre a teoria e a prática, unificando a execução com o conceito para transformar a realidade. O estudo contribuiu para compreender melhor as dificuldades que os alunos do curso de automação industrial encontram para aprenderem o desenho técnico, quais áreas possuem maior dificuldade e como intervir para reforçar os conceitos básicos, visando à formação profissional do estudante.

Este estudo tem como objetivo apresentar uma proposta de intervenção para o ensino do desenho técnico na formação dos alunos do curso do ensino médio Técnico em Automação Industrial, do IFSP de Birigui, em que foi constatado um déficit de aprendizagem dos conceitos básicos do desenho técnico, após pesquisa realizada com os alunos e o professor.

\section{Revisão de literatura}

\subsection{Desenho técnico: conceito}

Desenhar é um dos meios mais impactantes pelos quais podemos nos comunicar, tendo a capacidade de exceder as definições escritas e verbais. Há um ditado popular que elucida bem a utilidade da comunicação pelo desenho: "Entendeu, ou quer que eu desenhe?". Mas para que o desenho deixe de ter um viés unicamente estético, criou-se o desenho técnico, que tem por objetivo aprimorar, universalizar e normatizar as interpretações realizadas pelas expressões gráficas.

Para Ribeiro et all (2004), o desenho é uma forma de comunicação e registro visual, tendo potencial de retratar algo em um âmbito bi ou tridimensional por meio de múltiplas ferramentas ou métodos. Um desenho pode ser figurativo, abstrato ou simbólico, em outras palavras, pode se referir a uma imagem exata daquilo que representa ou produzir emoções. Desde os tempos antigos até os dias atuais, os desenhos surgem com a finalidade de documentar através de registros visuais o que se realizou, podendo ser analisado, planejado, estético ou traduzir expressões artísticas.

De acordo com Maguire e Simmons (2004), compreende-se por desenho técnico o conjunto de conceitos normativos para representação visual de objetos. O seu propósito é prover as informações essenciais para analisar o produto, auxiliar a projetá-lo e descomplicar sua concepção ou manutenção.

O desenho técnico pode ser concebido com recursos tecnológicos ou manuais. Existem programas (softwares) que possibilitam realizar projeções e cálculos que auxiliam no desenho, 
dispondo de diversas ferramentas prontas para a concepção de formas como: circunferências, retângulos, linhas auxiliares, instrumentos para a realização de medições e cotagens, dentre outas. As ferramentas manuais mais utilizadas são: régua, esquadro, compasso e lapiseira (CRUZ, 2014).

Portanto, as atuações do desenho técnico comumente são contempladas em áreas do desenvolvimento humano, atendendo de maneira efetiva o registro e a comunicação de informações. Pode ser considerado uma ferramenta imprescindível para o trabalho no âmbito da tecnologia, engenharias e arquitetura, possuindo características singulares que possibilitam a interpretação, a análise e sobretudo, a determinar procedimentos para intervenções bemsucedidas sobre a realidade.

\subsection{Ensino do desenho técnico manual e assistido pelo computador}

A habilidade criativa está ligada à capacidade de externar ideias, e o desenho manual é a uma maneira acessível e ágil de representar tais princípios. Contudo, com o crescimento dos recursos tecnológicos, surgiram novas formas de administrarmos os desenhos, com o propósito de simplificar e não substituir seus fundamentos. Rejeitar ou repudiar a tecnologia é inapropriado, visto que tal recurso está cada vez mais em evidencia, mas o desenho à mão nunca se tornará dispensável, pois este conhecimento é importante para o desenvolvimento das habilidades exigidas de um profissional capacitado.

De acordo com Ching (2011), embora a evolução da tecnologia, o desenho manual tem a capacidade de exceder um plano bidimensional e caracterizar os desenhos tridimensionais de maneira correta, compreensível e indubitável. Por isto, é necessário aprender a realizar e ler a linguagem gráfica do desenho. A realização do desenho não se limita apenas à técnica, mas é também uma atividade cognitiva que abrange a percepção visual, a abstração de dimensões e as relações espaciais.

Consoante e de modo complementar a esta afirmação, Marques e Chisté (2016) dizem que reconhecer a importância do estudo sistematizado unificando as ferramentas tradicionais do desenho técnico à computação gráfica e tendo a atenção de que a simples transferência do desenho manual pelo assistido por computador pode ter consequências prejudiciais no desenvolvimento da visão espacial e no raciocínio do educando, e isso é devido à ausência do manuseio de objetos e do esboço manual do desenho. Por outro lado, esses princípios podem ser realçados com o uso do computador, pois é um instrumento que pode acrescentar dinamismo à aula, além de estimular o conhecimento da geometria descritiva, auxiliar na produção de objetos tridimensionais e inserir maior proatividade nos alunos em função da facilidade com o manuseio da tecnologia.

Há docentes que argumentam sobre a extinção do desenho técnico manual. Entretanto, pesquisadores como Harris (2006) e Kempter et all (2012), os quais concentraram seus estudos no assunto, vivenciaram, em sala de aula, iniciar o ensino do desenho técnico no computador e concluíram que tal método afetou o aprimoramento da percepção espacial dos alunos, consequentemente aumentando o nível de reprovação. Por esta razão, os autores salientam a importância do período instrumental da disciplina, na qual várias atribuições cognitivas são desenvolvidas, mas também ressaltam a necessidade da implementação de tecnologia nas aulas, através da computação gráfica.

Mesmo que os deslumbrantes meios tecnológicos sintetizem a representação e a 
modelagem virtual de desenhos, mantem-se a origem do pensamento humano sobre a criação de projetos, assim sendo, aquele que operar o computador continuará a ser compelido a compreender o seu funcionamento básico e a sujeitar-se às decisões operacionais. Principalmente nas ocorrências em que nem todas as informações ou variáveis estão disponíveis (MONTENEGRO, 2005).

Portanto, ambos meios são significativos e não suprimem a existência um do outro, embora sejam distintos em suas fases operacionais, o desenho manual e a utilização de programas computadorizados exercem participações complementares em nossos dias. Os softwares correspondem ao aprimoramento nos projetos técnicos, possibilitando estabelecer representações precisas e rápidas mesmo em formas complexas. Já os desenhos manuais esclarecem, ordenam e estruturam as ideias, permitindo a fluidez entre o pensamento e o gesto manual.

\subsection{Ensino do desenho técnico 3D}

A aproximação da computação gráfica ao desenho técnico está em constante evolução, sendo uma ferramenta significativa de inovação tecnológica para contribuir no processo do ensinoaprendizagem. As aplicações dos programas 3D podem auxiliar na superação de obstáculos apresentados pelos alunos, ajudando-os a compreender a visualização espacial e a elaboração de projetos complexos, além de fornecer uma vasta gama de ferramentas, por meio da tridimensionalidade.

De acordo com Almacinha (2013), o desenho 3D começou a evoluir a partir dos anos de 1990 com a expansão da computação gráfica e dos sistemas CAD (computer aided design), possibilitando compreender a modelagem geométrica tridimensional (altura, comprimento e largura) de forma paramétrica, sendo eficaz na determinação e representação, solucionando dúvidas nas concepções espaciais e agindo diretamente no ambiente 3D. E, dessa forma, trouxe consigo recursos que proporcionam dados que podem ser analisados como: massa, volume, reações do comportamento e da estrutura de materiais, propiciando simulações de resistência, esforços e fadiga (MONNERAT).

Para Bento e Gonçalves (2011), na ocasião em que se objetiva formar um elemento tridimensional com características especificas de maneira a ser educativo, é indispensável entender os elementos que constituem a área do 3D. O seu uso em contexto educativo tem crescido conjuntamente ao nível da criação de objetos de aprendizagem para explicar determinados conteúdos, pois, com a tecnologia 3D, surgem aplicações em ambientes tridimensionais cada vez mais realistas. Entretanto, a utilização de ambientes virtuais 3D em plataformas educativas ainda se encontra numa fase inicial (BENTO; GONÇALVES 2011).

Segundo Pancini (2013), atualmente os programas 3D são empregados em muitos campos, pois é um instrumento significativo quando se referem aos trabalhos de engenharia, arquitetura e design, entre outros. Por conseguinte, no momento atual, é difícil os especialistas correlacionados a essas áreas renunciarem o uso desse tipo de ferramenta.

Os softwares 3D mais reconhecidos e aplicados no âmbito das áreas de projetos são: Rhinoceros $^{\circledast}$, Catia $^{\circledR}$, SolidWorks $^{\circledast}$, Autodesk $^{\circledR}$ AutoCad $^{\circledR}$, Autodesk $^{\circledR}$ Revit Architecture $^{\circledR}$ e Autodesk $^{\circledR}$ Inventor $^{\circledR}$, que permitem salvar os desenhos em diversas extensões (PANCINI, 2013). Pode-se também encontrar no mercado várias ofertas de software de desenho 3D em versões livres e comerciais que permitem desenvolver desde pequenas estruturas tridimensionais a complexos jogos em ambiente 3D (BENTO; GONÇALVES 2011). 
O desenho técnico 3D apresenta-se como uma ferramenta muito útil, devido à fácil compreensão e interpretação dos projetos de maneira plena. Os mecanismos tridimensionais representam com exatidão os resultados dos projetos, com informações detalhadas sobre resistência e simulação de materiais, cores, textura, áreas e proporções, facilitando a assimilação e observação do interior e exterior dos elementos, viabilizando a transposição do desenho para a realidade.

\section{Materiais e métodos}

A abordagem utilizada neste estudo é constituída de um plano de ação, embasado nas metodologias de pesquisa-ação, pesquisa de campo e bibliográfica. 0 estudo é dividido em duas macroetapas (figura 1): a identificação dos problemas no processo de ensino-aprendizagem na matéria de desenho técnico do curso de automação industrial; e uma proposta de intervenção pedagógica no sistema de ensino.

Mediante o objetivo de intervir na realidade a ser pesquisada, o trabalho se aproxima da pesquisa-ação, visto que é o modo de averiguação no qual empregam-se métodos de pesquisas intencionais a fim de definir ações, visando a melhorar e modificar tanto o fato do cenário pesquisado quanto a prática estabelecida, complementa o autor. Possuindo fundamentos a viabilizar a práxis, logo, a pesquisa-ação busca ligar a pesquisa à ação ou realidade, expandindo o conhecimento e a percepção com a prática. Para Morin (2004), a pesquisa-ação deve ter uma perspectiva integral sistêmica, abarcando cinco categorias principais: contrato; participação; mudança; discurso e ação.

Figura 1 - Exemplo de imagem

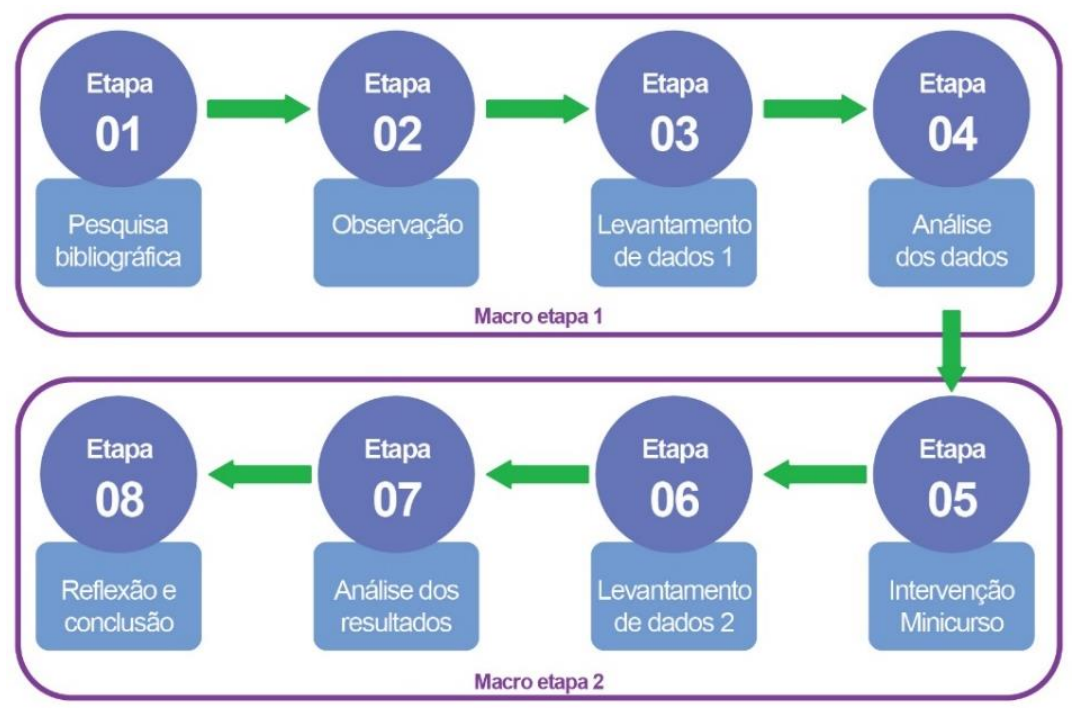

Fonte: Elaborado pelo autor.

Os instrumentos empregados para coleta de dados foram a observação e a pesquisa quantitativa-qualitativa estruturada, que, de acordo com Marconi e Lakatos (2011), é uma identificação do método científico que dispõe de diversas técnicas estatísticas para medir concepções e informações de uma determinada área de estudo. Ela é empreendida para evidenciar 
o raciocínio lógico e todos os conhecimentos mensuráveis sobre as experiências humanas.

Nesta modalidade de pesquisa, as ferramentas para o levantamento de dados foram organizadas por meio de um roteiro predeterminado através de um questionário, aplicado em entrevistas individuais. Esses recursos possuíam questões compreensíveis e objetivas, tendo por finalidade obter padronização nas respostas para que possam ser confrontadas e analisadas, auxiliando na construção de gráficos norteadores. E estes, por sua vez, necessitaram ser desenvolvidos com rigidez para que se alcançasse a credibilidade necessária dos resultados.

Foram definidos como amostra os alunos do curso de automação industrial, de nível médio técnico, do Instituto Federal de São Paulo (IFSP) de Birigui. Todos os participantes eram do sexo masculino, com idade entre 16 e 45 anos. No total, foram aplicadas dez questões, sendo duas qualitativas descritivas e oito quantitativas, por meio das quais se pode compreender melhor o contexto do estudo proposto e identificar alguns problemas no processo de ensino-aprendizagem do desenho técnico.

Por fim, após o término da Macro etapa 1, que foi direcionada ao levantamento de problemas no ensino do desenho técnico, deu-se início imediato na Macro etapa 2, que consistiu no desenvolvimento de uma nova metodologia para o ensino, baseada em um minicurso. 0 minicurso foi aplicado nas mesmas condições (estrutura física) do modelo convencional utilizado pela instituição. Na sequência, foi aplicado um novo questionário, com o objetivo de entender e comparar as abordagens (tradicional e o minicurso). Ao final, foram comparados os dados e analisados os resultados.

\section{Resultados}

\subsection{Macroetapa 1}

\subsubsection{Observação e questionário}

A pesquisa se iniciou a partir das observações em sala de aula e da aplicação de um questionário, a fim de aprofundar a pesquisa e compreender as dificuldades no contexto do ensino do desenho técnico no curso de automação industrial ofertado pelo IFSP de Birigui, visando também sua configuração e a relação entre professor-aluno, bem como outras variáveis que interferem no processo ensino-aprendizagem.

A princípio, foi possível identificar que a classe possuía déficit de aprendizagem sobre os conceitos básicos do desenho técnico, como a compreensão da linguagem técnica, por exemplo: tangência, perpendicularidade e paralelismo. Além disso, os alunos não representavam, de maneira correta, as projeções ortogonais necessárias para a comunicação inequívoca do desenho, e não assimilavam a importância da disciplina para a formação do curso e sua aplicabilidade.

Nas atividades desenvolvidas através do software gráfico, foram observadas as dificuldades dos alunos no quesito visão espacial, no ato de relacionar deslocamento com ângulos e na interpretação e abstração das medidas que não estão explícitas nos desenhos (figura 2). Alguns pontos observados podem contribuir para esse cenário negativo, um deles é a falta de anotações durante a aula de desenho técnico, já que por se tratar de "desenho" os alunos se omitem a esse trabalho, resultando no baixo índice de memorização dos conteúdos e na falta de material de pesquisa extraclasse. 
Em consequência disso, o professor precisa explicar em todas as aulas, repetidamente, os mesmos conceitos e técnicas dos conteúdos a serem abordados, acarretando lentidão no desenvolvimento da aula e das atividades realizadas. Isso exige do professor um atendimento, muitas vezes, personalizado e, por ele não conseguir atender a todos os alunos ao mesmo tempo, alguns param de fazer os exercícios. Outro fator negativo é o fato de os alunos não desenvolverem as atividades extraclasses ocasionando um acúmulo de tarefas e diminuição da qualidade na entrega dos exercícios.

Figura 2 - Exemplo de abstração de medidas e projeção incorreta da vista lateral esquerda

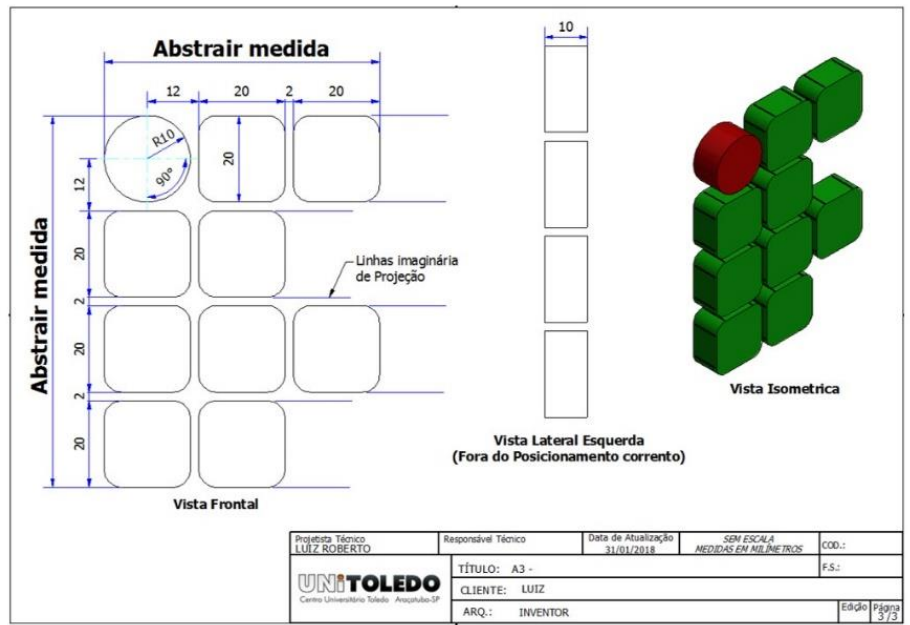

Fonte: Elaborado pelo autor.

Em relação ao professor, percebe-se que possui domínio pleno e aprofundado sobre o assunto, tem boa oratória e paciência com os alunos, tendo a atenção e o cuidado em orientá-los individualmente. Entretanto, as aulas e os exercícios, em sua maioria, são apresentados em slides e explicados oralmente, tornando-os repetitivos e desinteressantes (figura 3).

Figura 3 - Explicação do exercício

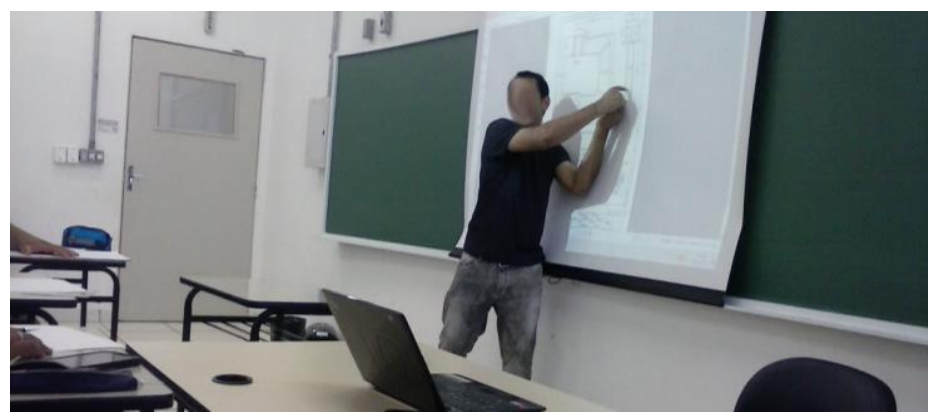

Fonte: $\mathrm{O}$ autor.

\subsubsection{Aplicação do questionário}

A seguir estão dispostos alguns gráficos referentes ao índice de respostas, relatadas pelos alunos, após aplicação do primeiro questionário. A princípio, foi questionado se eles consideravam adequados os equipamentos que são utilizados na disciplina de desenho técnico, e todos foram 
unânimes em afirmar que sim. Na pergunta a seguir, é possível identificar a desvalorização do desenho manual, ocasionada, talvez, pelo uso excessivo das tecnologias. O desenho manual é a uma forma acessível e pratica para representar ideias. Com a expansão dos cursos tecnológicos surgiram novas formas de manusearmos os desenhos técnicos, com o propósito de auxiliar e não substituir seus fundamentos (figura 4).

Figura 4 - Respostas à questão: Quais ferramentas e softwares você considera importantes para o aprendizado dessa disciplina?

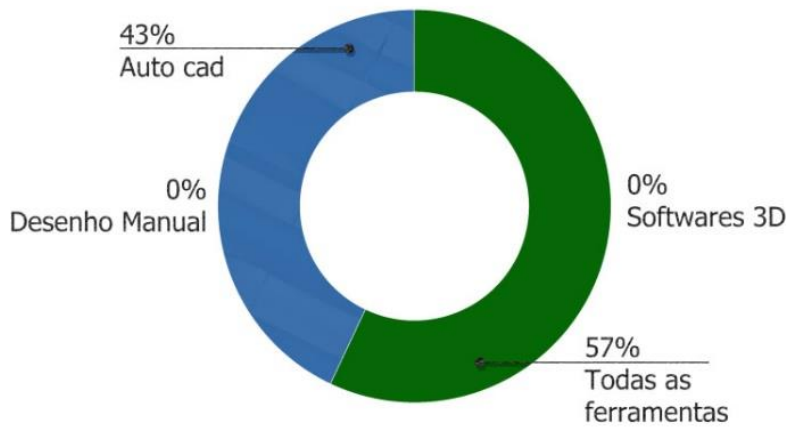

Fonte: $\mathrm{O}$ autor.

Na próxima questão, mesmo a maioria dos alunos tendo entendido a importância do desenho técnico para a formação do profissional da automação, uma parte não vê conexão com a área. Isso se torna um bloqueio para o aprendizado do indivíduo, pois ocasiona a falta de estímulos para o estudo da disciplina. Por este motivo, o estudante acaba por não absorver o conceito, tornando-se um profissional despreparado para o mercado de trabalho (figura 5).

Figura 5 - Respostas à questão: Dentro do curso de automação industrial, você considera importante o ensino do desenho técnico?

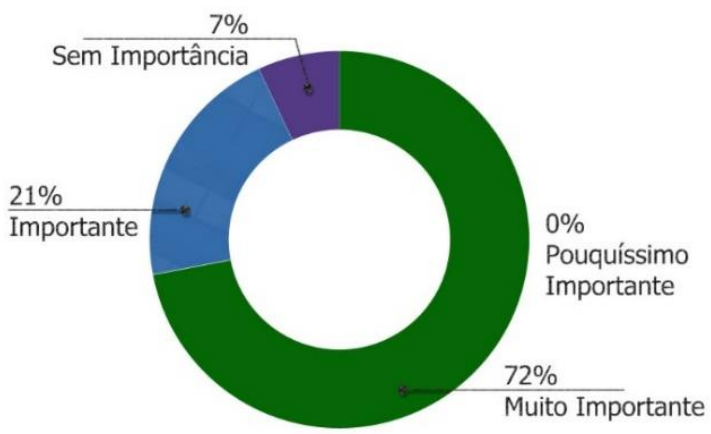

Fonte: $\mathrm{O}$ autor.

Na última questão, $43 \%$ dos entrevistados se auto avaliaram como tendo um conhecimento mediano acerca das projeções ortogonais, em relação à leitura, interpretação e criação das vistas ortográficas, sabendo-se que para uma comunicação eficaz entre os projetistas, especialistas, técnicos e clientes, as informações transmitidas pelos desenhos precisam ser nítidas e inequívocas para evitar desperdício, acidentes e otimizar a execução dos trabalhos. É possível que a outra parte, $57 \%$, que se auto avaliou como "Bom", não esteja realmente neste nível, pois parametriza seu 
entendimento dentro da percepção média da sala de aula.

A execução das formas espaciais é resolvida através da utilização das projeções ortogonais para que o desenho resultante se transforme em uma comunicação universal. Os planos de rebatimento precisam seguir as convenções, dessa forma, ao empregar os rebatimentos convencionados, é preciso entender o posicionamento correto de cada projeção, visando comunicar de maneira exata todas as informações necessárias do projeto. Esses alunos, em sua maioria, não demonstraram aptidão tanto para o uso das ferramentas quanto para o entendimento dos princípios do desenho técnico, sejam ele manual ou virtual.

\subsection{Macroetapa 2}

\subsubsection{Desenvolvimento do minicurso}

Com base nas observações em sala, na coleta, na análise dos dados do questionário e na entrevista realizada com o professor, foi proposto um plano de ação. O plano de ação baseou-se na aplicação de um minicurso com a utilização do software 3D (tridimensional) denominado Autodesk ${ }^{\circledR}$ Inventor ${ }^{\circledR}$, com duração do curso de 8 horas, realizadas em dois sábados no laboratório de informática da instituição no período das 8:00 às 12:00 horas.

O desenho técnico foi apresentado como forma de comunicação indispensável para o profissional da automação, buscando aproximar teoria e realidade, ajudando os alunos a compreenderem melhor as linguagens técnicas do desenho, os conceitos básicos das vistas ortogonais e os benefícios das anotações, mesmo que dentro de um curso de desenho. Para isso, o software 3D ajudou no entendimento da espacialidade virtual através das ferramentas de visualização. Isso facilita o desenvolvimento da percepção espacial do aluno e na projetação das vistas.

A princípio, foi desenvolvido um caderno de anotações individual impresso, em cuja capa havia um desenho técnico 3D do logo do IFSP com o título do minicurso e a identificação do programa que se iria apresentar. Na segunda página, foi criado um pequeno sumário com os temas a serem abordados, e nas páginas seguintes foram elaboradas imagens das interfaces do programa, com setas indicativas e linhas em branco, para que os alunos anotassem, com suas palavras, a utilização das ferramentas e os detalhes que achassem relevantes (figura 6).

Figura 6 - Capa, sumário e sequências das folhas do caderno de anotações.

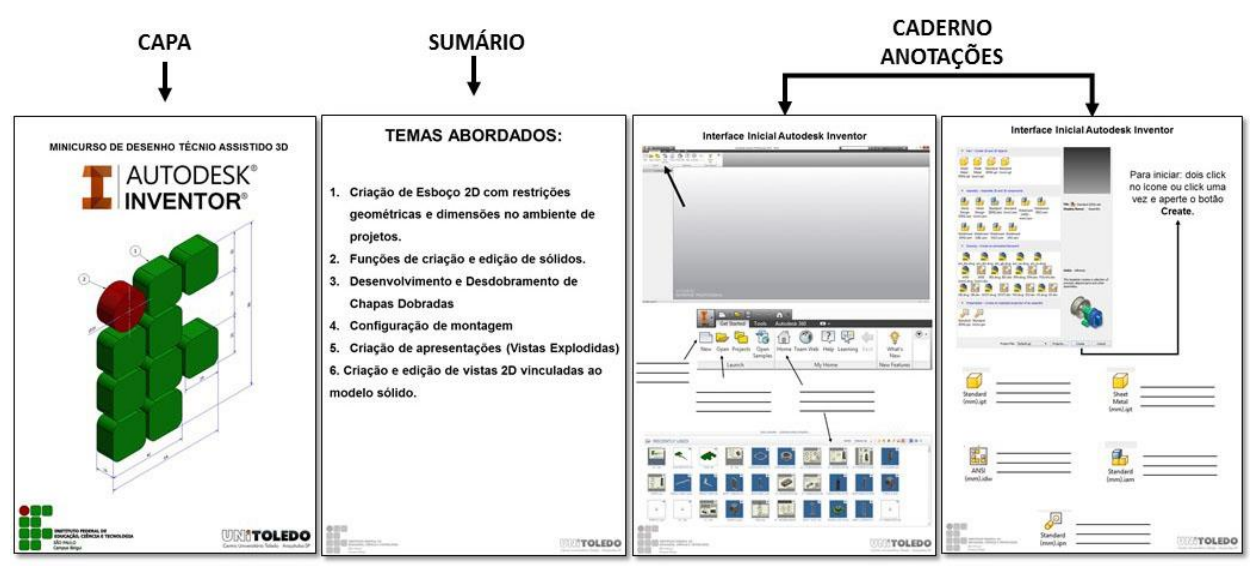


Fonte: Elaborado pelo autor.

Para a criação das atividades em forma de desenhos, foi observado que todas as salas do IFSP possuem sistema de eletrodutos externos (figura 7), sendo organizados por meio de canaletas, tubos, conexões e painéis. As peças e layout de construção dos eletrodutos são projetados pelo profissional da automação através do desenho técnico. Então, foi desenvolvida uma apostila de exercícios com 15 modelos de peças, que poderiam ser identificado no próprio ambiente da sala e da instituição, e, também foram utilizadas as peças reais (físicas) dos exercícios, que possibilitaram aos alunos realizar as medições e tirar dúvidas do modelo físico.

Figura 7 - Layout das instalações elétricas da sala de aula.

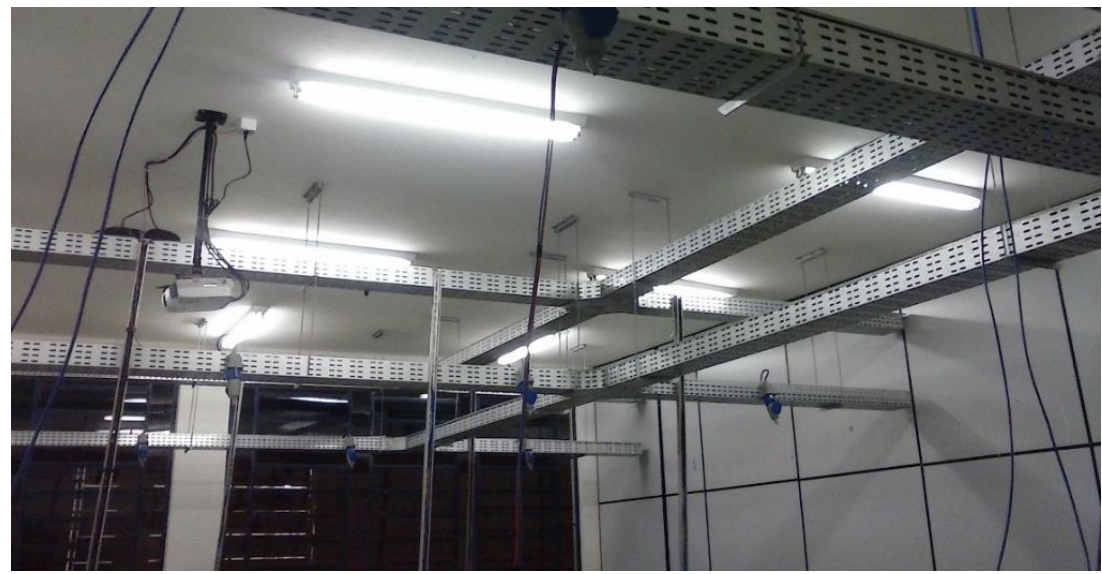

Fonte: $\mathrm{O}$ autor.

Para auxiliar na execução dos exercícios em classe e extraclasse, foram desenvolvidas dez videoaulas, nomeadas com seus respectivos temas, com duração de 1 a 8 minutos, criadas através do Screencastify ${ }^{\circledR}$, que é uma extensão do Google Chrome que permite aos seus usuários capturar som e imagem em vídeo da tela do computador de maneira rápida e prática, podendo gravar os vídeos com boas resoluções e permitindo armazenar as gravações no Google Drive ou no próprio computador.

\subsubsection{Aplicação do minicurso e análise dos resultados}

No início do minicurso, foi feita uma explanação introdutória oral a respeito do conteúdo a ser trabalhado e quais eram os objetivos do minicurso. Além disso, os alunos foram conscientizados acerca do perfil do técnico em automação Industrial e da necessidade de estarem preparados para realizar atividades de planejamento, execução, manutenção e automação em diversos tipos de segmentos. Estas áreas necessitam do desenho técnico para que haja uma comunicação integrada e precisa, e, para isso, o uso de programas tridimensionais mais sofisticados, utilizados para a criação e compreensão dos trabalhos futuros, se torna um diferencial.

Para iniciar a fase operacional, foi entregue o caderno de anotações e dada uma breve explicação de sua importância para o minicurso, juntamente com a lista de peças a serem desenvolvidas. Foi enfatizado que os eletrodutos fazem parte do cotidiano do profissional da automação e que estão em todas as salas da instituição. $O$ aluno teve como atividade projetar as 
peças tridimensionalmente no software e entregar o layout do projeto técnico ao final. Todas as peças criadas foram feitas simultaneamente pelos alunos e pelo instrutor, que fez a transmissão ao vivo pelo projetor. Além disso, as videoaulas foram repassadas para os alunos por meio de um pendrive no começo da aula, enquanto as peças físicas foram expostas sobre mesas por todo o ambiente da sala para que os alunos pudessem abstrair medidas e tirar dúvidas pertinentes à sua projetação.

A representação das vistas ortogonais são as projeções utilizadas para representar as formas tridimensionais através de figuras planas, e, para compreender melhor este conceito foram utilizadas duas ferramentas, uma a partir das peças reais, nas quais pode-se manipular e visualizar os posicionamentos corretos e, a outra, através da ferramenta Viewcube do programa da Autodesk ${ }^{\circledR}$ Inventor $^{\circledR}$, que auxiliou na colocação do modelo em vistas paramétricas, disponibilizadas automaticamente por meio de sua manipulação (figura 8).

Figura 8 - Auxílio da ferramenta Viewcube do Autodesk ${ }^{\circledR}$ Inventor $^{\circledR}$.
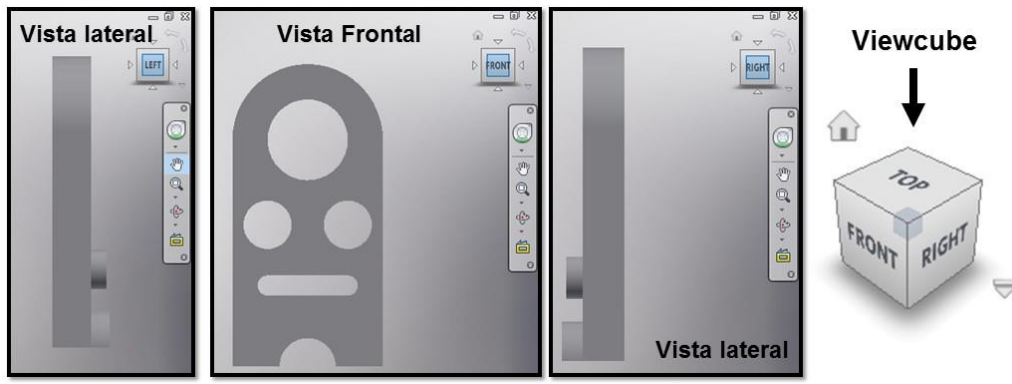

Fonte: Elaborado pelo autor.

Ao final, após a execução dos exercícios e a criação individual dos layouts, foi aplicado outro questionário para dimensionar se os objetivos foram alcançados, também para aperfeiçoamento e esclarecimentos, tendo em vista que, além de ajudar os alunos nas dificuldades relacionadas com o desenho técnico, também se incluiria uma nova experiência por meio do contato com o programa tridimensional. Abaixo seguem as perguntas do questionário e as respostas apresentadas pelos alunos na disposição de gráficos.

Figura 9 - Respostas à questão: Com o auxílio dos desenhos gráficos tridimensionais houve uma melhor percepção e entendimento das vistas ortogonais?

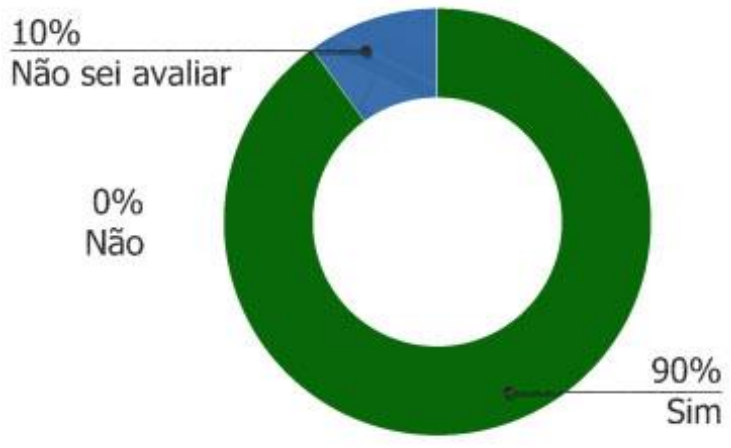

Fonte: Elaborado pelo autor. 
Introduzir o uso da tridimensionalidade virtual no ensino do desenho técnico mostrou-se um meio muito positivo, o que contribuiu para melhorar a compreensão e interpretação das vistas ortogonais, pois houve uma resposta satisfatória, facilitando a assimilação e abstração dos elementos (figura 9). Anteriormente, ao se questionar os alunos sobre o domínio da localização espacial, foi obtida a marca de $14 \%$ dos alunos que acreditavam não ser importante o aprimoramento desta habilidade. Já com a aplicação do minicurso e com o auxílio da ferramenta Viewcube do programa da Autodesk ${ }^{\circledast}$ Inventor ${ }^{\circledast}$, acredita-se ter havido melhor compreensão deste conteúdo. Contudo, mesmo alguns alunos ainda apresentando incertezas sobre o assunto, pode-se aprofundar o entendimento acerca da percepção espacial, demostrado pelos $72 \%$ de respostas positivas na figura 10 .

Figura 10 - Respostas à questão: Após a utilização da ferramenta Viewcube do programa da Autodesk ${ }^{\circledR}$ Inventor $^{\circledR}$, houve uma melhor compreensão sobre visão espacial?

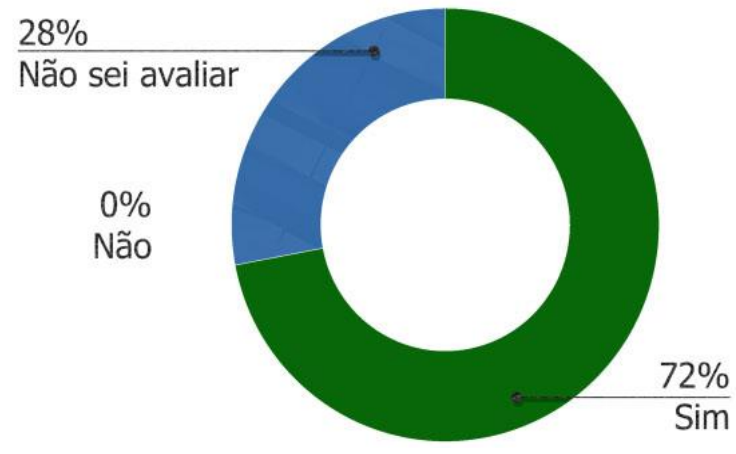

Fonte: Elaborado pelo autor.

Os dados, coletados sobre a utilização de peças físicas no ensino do desenho técnico, consistem em informações de relevância sobre a transposição da teoria imaterial e abstrata para o contato com o mundo real. Sabendo-se que, ao inserir tais atividades, pode-se proporcionar a oportunidade de unir teoria e prática para uma melhor formação profissional, deve-se possibilitar ao aluno a aquisição de experiência, familiarização e identificação com elementos do universo da prática profissional (figura 11). A maioria classificou essa abordagem como algo muito importante para a formação de sua experiência, refletindo certamente, o interesse durante as aulas.

Figura 11 - Respostas à questão: Foi relevante o uso de peças físicas em mãos para melhor percepção e entendimento do desenho técnico?

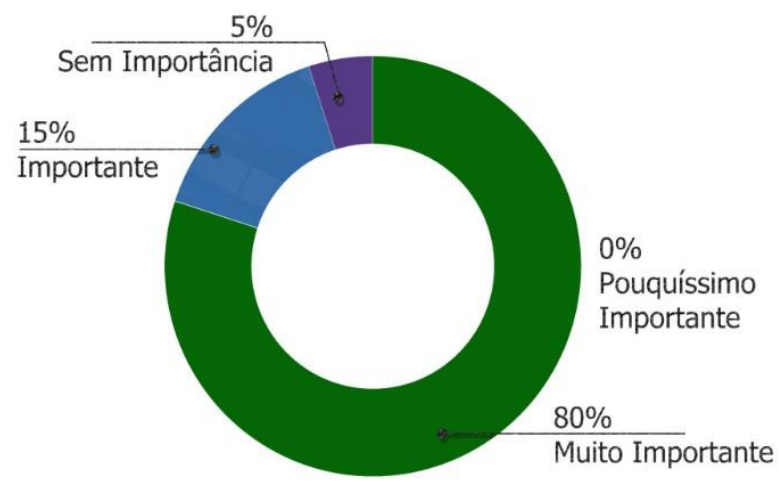

Fonte: Elaborado pelo autor. 
Esta fase de coleta das informações, após a aplicação da intervenção, teve como objetivo analisar qual foi a relevância da pesquisa em relação aos problemas levantados, procurando ponderar não apenas as informações positivas, mas também os pontos contrários para garantir a credibilidade dos resultados. Importante observar que o questionário consiste apenas em um instrumento para facilitar a interpretação da repercussão do trabalho e que, para uma melhor compreensão desses aspectos, há a necessidade de constantes pesquisas para obtenção de melhores resultados.

\section{Conclusão}

Este trabalho buscou analisar e intervir no sistema de ensino do desenho técnico, na formação dos alunos do curso médio Técnico em Automação Industrial, do IFSP de Birigui. Foi constatado um déficit de aprendizagem dos conceitos básicos do desenho técnico, como a compreensão da linguagem técnica, a representação correta das projeções ortográficas, a omissão por parte dos alunos em anotar as explicações e a falta de compreensão da importância da matéria para sua formação.

As áreas de formação técnica ou tecnológica têm como base curricular o ensino do desenho técnico, mas é possível observar uma deficiência sobre tal matéria, que se faz importante para a execução de tais funções. Ao fim dos módulos de desenho técnico, os alunos não possuem habilidades mínimas que seriam as de interpretar, analisar e desenvolver projetos, fazendo-se necessária a intervenção com o intuito de aprimorar este processo, que se encontra estagnado, desinteressante e obsoleto.

Mediante esta pesquisa, foi identificado que os alunos recebem poucos estímulos relacionados durante as aulas e que a abordagem pedagógica se baseia na repetição de informações provindas do professor. Isso pode fazer com que os alunos criem barreiras para o aprendizado, por não entenderem o propósito e a importância do conteúdo, propiciando o desinteresse, a falta de anotações e supervalorização dos programas gráficos. Dispondo, muitas vezes, apenas do "domínio" dos softwares, que não podem alicerçar ou substituir os conceitos normativos que fundamentam o desenho técnico. O que se deve concluir, provisoriamente, é que há necessidade da aproximação pedagógica com as práticas do mercado, mesmo em ambiente acadêmico.

\section{Referências}

\section{ALMACINHA, J. A. A Modelação em CAD 3D e a Especificação Técnica no Desenvolvimento de}

Produtos. Parte 1: Visão geral sobre a evolução da documentação técnica para a definição e a especificação de produtos. Porto: NOS-INEGI, 2013.

BENTO, João José Fernandes; GONÇALVES, Vitor. Ambientes 3D no processo de ensino e aprendizagem. EduSer-Revista de educação, p. 45-58, 2011.

Ching, F.D.K (2011). Representação gráfica em arquitetura. Porto Alegre: Bookman.

BONI, Cláudio R.; PASCHOARELLI, Luiz C.; SILVA, José C. P. Intervenção ergonômica em misturador externo de água para residências com aquecimento. Intervenção ergonômica em misturador externo de água para residências com aquecimento solar. Anais do 13을 Ergodesign e 13은, 
Juiz de Fora:UFJF, 2013.

FERREIRA, Rita Cristina. Uso do CAD 3D na compatibilização espacial em projetos de produção de vedações verticais em edificações. 2007. Tese de Doutorado. Universidade de São Paulo.

FREIRE, Paulo. Conscientização: teoria e prática da libertação: uma introdução ao pensamento de Paulo Freire. Cortez \& Morales, 1979.

Harris, A. N. (2006, agosto). Aplicação e resultados de uma nova didática para a disciplina de desenho técnico no curso de engenharia civil da FEC-Unicamp. Anais do $5^{\circ}$ Encontro Regional de expressão gráfica, Salvador, Bahia, Brasil, 10.

Kempter, E., Corghi, F.N., Ferraz, A. L. \& Costa, D.C. (2012, setembro). Desenho técnico aplicado aos cursos superiores de tecnologia ambiental e construção civil. Anais do XI Congresso Brasileiro de Educação em Engenharia, Belém, Pará, Brasil, 12.

MAGUIRE, D. E.; SIMMONS, C. H. Desenho técnico: problemas e soluções gerais de desenho. São Paulo: Hemus, 2004.

MARCONI, Marina de Andrade et al. Técnicas de pesquisa. São Paulo: Atlas, 2011.

MARQUES, Janaina Carneiro; DE SOUZA CHISTÉ, Priscila. O Ensino do Desenho Técnico: uma Proposta Interdisciplinar. CIAIQ2016, v. 1, 2016.

MONTENEGRO, Gildo A. Inteligência visual e 3D: Compreendendo conceitos básicos da geometria espacial. São Paulo: Edgard Blucher, 2005.

MORIN, A. Pesquisa-ação integral e sistêmica: uma antropopedagogia renovada. Rio de Janeiro: DP\&A, 2004.

PANCINI, Marcelo Taborda. O uso do modelo 3D durante a projeção do conceito Cussion Folder Gluer. 2013.

RIBEIRO, Carlos Tavares; DIAS, Carlos Tavares; SOUSA, Luís. Desenho técnico moderno. 4a edição, LTC, 2004.

SEVERINO, Antônio Joaquim. Metodologia do trabalho científico. Cortez editora, 2017.

TRIPP, David. Pesquisa-ação: uma introdução metodológica. Educação e pesquisa, v. 31, n. 3, 2005.

VELOSO, P. L. A. (2010). Modelagem digital na arquitetura contemporânea. In I Encontro Nocional de Pesquisa e Pós-graduação em Arquitetura e Urbanismo (ENANPARQ), Rio de Janeiro, Brasil. 